\title{
An economic analysis of attendance demand for One Day International cricket
}

\author{
Abhinav Sacheti, Ian Gregory-Smith and David Paton
}

\begin{abstract}
The future of One Day International (ODI) cricket has come under scrutiny following increasing competition from other formats of cricket. We identify trends in attendance demand by examining over 540 ODI matches played in Australia and England between 1981 and 2015. We use fixed effects and Tobit random effects models to isolate key determinants of attendance demand for ODI cricket and in particular the impact of uncertainty of outcome. We find that team strength has little independent effect on ODI attendances, but the uncertainty of the match outcome, as measured by the relative strengths of the teams over a long period of time, increases demand for ODI matches in England. Further, organising the ODI as a Day/Night (floodlit) game has a large positive impact on attendance in Australia.
\end{abstract}

Keywords: demand, uncertainty of outcome, cricket.

JEL codes: C23, L83, R22 


\section{An economic analysis of attendance demand for One Day International cricket}

\section{Introduction}

One Day International (ODI) cricket is an important format of the game that allows two nations to complete a competitive match inside one day. However, attendances at ODI matches in some countries have fallen substantially over recent years: for example, attendances in the $1980 \mathrm{~s}$ in Australia averaged over 35,000 but struggle to reach 25,000 today. The decline has accelerated since the first ICC World Twenty20 International (T20I) championship in 2007. Given the success of the Twenty20 format, some commentators have questioned whether ODI cricket has a future at all ${ }^{1}$ though notably the 2015 World Cup final between New Zealand and Australia was played in front of a record crowd of 93,013.

In this study we seek to identify the demand for ODIs over time. Using attendance data for over 540 ODI matches played by home teams in Australia and England between 1981 and 2015, we estimate whether uncertainty of outcome and the strengths of the teams involved can explain demand for ODI cricket. The length of our dataset enables us to observe trends over a number of eras: the 1980s, when ODI cricket grew as a rival to Test cricket; the 1990s, when ODI cricket arguably usurped the popularity of Test cricket and the 2000s onwards, where ODI cricket's relevance has been challenged by T20I cricket.

Our choice of Australia and England was motivated by the fact that these countries provide two of the biggest markets for ODI cricket in the world, whilst ODIs have a long history in each country. From a practical point of view, these are also the two countries for which attendance data are available for a significant period. A feature of this paper is that we are able to exploit variation in strengths between different away teams and variation in the relative strengths of these teams over time. We use fixed effects, and where attendance is constrained by the capacity of the ground, Tobit random effects models to identify the uncertainty of outcome effects. We are also able to control for economic and other factors (such as the weather) that have been noted to affect demand for sport in the literature.

The structure of the paper is as follows. In the next two sections, we provide a brief introduction to ODI cricket and motivate our focus on uncertainty of outcome with reference to the prior literature. In section 4, we explain the methodology and data used in this study. That the game concludes in a day avoids one measurement problem of the Test cricket setting, whereby the evolution of the match itself can affect demand for the latter days' play.

\footnotetext{
${ }^{1}$ See for instance http://www.espncricinfo.com/infocus/content/story/infocus.html? subject=39.
} 
In section 5, we present the descriptive statistics and results before providing some discussion and concluding comments in section 6.

\section{History of ODI cricket}

Limited overs cricket was first played in England 50 years ago, in response to dwindling attendances for the first-class format of domestic cricket (Schofield, 1982). The first limited overs game between countries was played between England and Australia in 1971. This format of the sport has since been called ODI cricket. The International Cricket Council (ICC), the governing body of international cricket, allows the ten Test nations and a number of other member nations (given "associate" or "affiliate" status) to play ODI cricket. An ODI game is played one innings a side: a team needs to score more runs than the other team to win the match. ODIs were initially played at sixty overs an innings, but over the last two decades they have been played at fifty overs an innings. In contrast to Test cricket, where a draw is possible, weather permitting each ODI ends with a definite result: either a win for one side or (rarely) a tie.

ODI cricket is an important setting to study attendance demand because it represents a balance between the shorter Twenty20 format, played for 20 overs per innings, and the lengthier Test cricket format, the original format of international cricket which can last up to 5 days. As such, ODI cricket provides a stepping stone for the next generation of cricket fans and families seeking an accessible format of cricket, but one that nonetheless rewards a style of play that could also be successful in Test cricket. Moreover, one-day cricket is the typical format replicated by amateurs in weekend games (e.g. between village cricket clubs) and revenues from ODI cricket are important in funding domestic cricket in a number of countries.

The ODI format has also been used as a format to encourage development in newer cricketing countries such as Ireland and Afghanistan. The recent decision to exclude such "associate" teams from the next ODI World Cup (to be hosted by England in 2019) has been particularly contentious and we consider the implications of this decision in the conclusion.

\section{Uncertainty of outcome}

Whether or not uncertainty of outcome impacts demand for sport has been the subject of much debate since Rottenberg (1956) (see Borland and Macdonald (2003) for a review of the extant literature). For example, Borland (1987) looks at the effect of uncertainty of outcome 
on demand for Australian rules football; Peel and Thomas (1988) examine the impact of uncertainty of outcome in soccer and King et al. (2012) assess the influence of playoff uncertainty on attendance in Australian National Rugby League matches.

In line with this tradition, the prior literature on demand for international cricket (including Chapman et al. 1987; Hynds and Smith, 1994; Bhattacharya and Smyth, 2003; and Blackham and Chapman, 2004) has sought to determine whether uncertainty of outcome impacts demand by looking at Test matches. Using uncertainty of outcome measures based on the relative strengths of teams in recent games, the results from these studies are broadly consistent with the hypothesis that a match between two competitively balanced teams is likely to have a positive impact on attendance demand. Sacheti et al. (2014) add to this literature by incorporating an additional measure which captures the uncertainty of outcome over a longer period of time (which they call long run uncertainty of outcome). The finding there shows that placing relative qualities of the two teams in a historical context is very important when explaining the demand for Test cricket. In particular, Sacheti et al. (2014) note that in both England and Australia, the absolute strengths of the home and away teams increase demand, whereas the relative long term strengths of teams have little effect.

Despite the work on Test cricket above, to our knowledge there is no study that has examined demand for ODI cricket. This is surprising given there are good reasons to suspect that the demand for ODIs will be different to Test cricket. As noted above, ODI cricket is a substantially shorter format of the game than Test cricket and is also marketed as a different product to Test cricket. It is quite possible that ODI cricket attracts a different type of spectator to Test cricket $^{2}$. Moreover, Test matches are played over a period of days and uncertainty of outcome can change within match, whereas in ODI cricket uncertainty of outcome is based only on the ex-ante win probabilities of the two teams. The fact that limited overs cricket was deliberately conceived in response to dwindling attendances for first class cricket is also highly suggestive that demand for the two formats of the game is different.

Additionally, while there has been prior work on one-day cricket, these studies have been restricted to domestic cricket (Paton and Cooke, 2005; 2011). The market for one-day international cricket is of an order of magnitude larger than for domestic cricket. As such, it is not reasonable to assume that the results from domestic one-day cricket will carry over to an international setting. Since we have no a priori reason to assume the results from literature

\footnotetext{
${ }^{2}$ One key difference between Test and ODI cricket is the concept of a "draw" in Test cricket. Barring weather interruptions, ODI matches produce a result in most cases. Test matches are played over five days and if there is no outright result in the match, the Test match is simply "drawn".
} 
on Test matches or domestic limited overs games will transfer to the ODI context, we believe it is important to investigate this format of the game.

\section{Methodology}

\subsection{Data}

For matches in Australia, the data contain match attendance for 340 ODIs played by the Australian cricket team in Australia between January 1985 and March 2015. The England data contain match attendance for 202 ODIs played by the English cricket team in England between January 1981 and March 2015. Attendance data for some matches were unavailable. In total, there are 542 ODI matches in our sample, representing over $15 \%$ of the full population of ODIs played in all countries as of March 2015.

Data on match attendances were mostly collected from Wisden Cricketers' Almanack annual editions between 1981 and 2014. In the minority of cases for which Wisden did not report attendances, data were collected directly from venue authorities or from the Austadiums.com web site. Match related data, including dates, venue, opposition and series and final day uncertainty were collected from the ESPNcricinfo web site. Data on rain were collected using the ESPNcricinfo web site and match reports in various Wisden Cricketers' Almanack editions.

Following Hynds and Smith (1994), data on earnings were collected from national income surveys. The measure used was the average weekly wage for all workers, and where unavailable, all male workers in the catchment area for the match venue. The wage data were adjusted for inflation using relevant price indices. Data on venue capacities were collected from venue authorities. Data on competing sports events and public holidays in both countries were collected using widely available public sources, such as official web sites for the Australian Open and Wimbledon, and government web sites listing public holidays.

\subsection{Empirical modelling}

The data used in this study are in panel form, as they comprise both time series and cross sectional elements: a number of venues host matches annually over the sample period. As Koop (2008) explains, in many panel data situations involving people, countries or companies, the assumption of a common regression model is unreasonable due to likely heterogeneity. Panel data analysis enables estimation of aspects of individual heterogeneity in a way that is not possible using cross-sectional data. Using Ordinary Least Squares (OLS) 
is likely to produce biased and inconsistent estimates (Wooldridge, 2010) because some unobservable factors are likely to be fixed at particular venues. For the Australia estimates, we choose between using a venue fixed effects or random effects model. A Hausman test favours the former, but in practice our results using a random effects model are very similar.

In the case of the England matches, there is an issue relating to 'censoring' of attendance. Censoring occurs when demand is greater than observed due to capacity constraints in the stadia. Paton and Cooke (2005, p.34) note "artificial censoring of attendance is a common feature of sports attendance models, and the use of OLS methods can lead to biased results." Many matches in our sample of England matches are supply constrained as attendance on the day is at, or very close to, the venue capacity. In Australia, where the grounds are much larger, censoring is usually not an issue as the grounds rarely sell out.

To correct for a similar problem, Lemke et al. (2010) used censored normal regression techniques in their study of demand for Major League Baseball (MLB) in the USA. They argued that error terms are likely to be correlated across games within each series of games because baseball games are played in series against the same opponent for three to four consecutive games. Honoré (1992) shows that a fixed effects Tobit model produces biased estimates so we use a random effects Tobit model for English ODI attendances instead. The fact that the Australian fixed effect estimates are very close to the Australian random effects estimates provides us with some reassurance that failing to control for fixed effects in the English matches is unlikely to be the cause of the difference between the two countries. In some cases, it is difficult to precisely determine whether the matches were capacity constrained or not. Even if attendance on the day is not at $100 \%$ capacity, it is possible that some potential spectators might have been unable to buy tickets (e.g. if some spectators holding tickets do not attend on the day). As a rough, but conservative correction for this problem, matches where attendance was over $90 \%$ of the reported venue capacity were considered to be censored.

\subsection{Measuring Attendance}

Variable definitions and sources are given in Table 1. Our dependent variable, Attendance, is the number of spectators who officially entered the venue for the match. We have used live attendance to model demand for reasons of data availability. An alternative measure of live demand is number of tickets sold, but we expect this to strongly correlate with attendance. A 
further alternative was to use some measure of television or radio audiences but these data were not accessible. Use of more recent forms of media such as Internet broadcasts would restrict our sample to a relatively small number of years.

We have two sets of attendance data: one for attendance at ODIs played by home teams in England and one for attendance at ODIs played by home teams in Australia. We will estimate a linear and a log-linear specification of equation 1 (provided in section 4.5 below). The use of a log-linear model in addition to a linear specification is motivated by the ability of the former model to show how elastic demand is to unit increases in the explanatory variable as well as the use of these specifications in the literature on demand for sport (e.g. Falter and Perignon (2000) and Bhattacharya and Smyth (2003) both employ a log-linear specification as part of their studies).

Attendance demand is a function of home team strength (Home Strength); opposition team strength (Opposition Strength); the absolute difference in team strengths (Ratings Certainty); the square of absolute differences in team strengths (Ratings Certainty Squared); uncertainty of outcome about the series or tournament outcome (Series Certainty); whether the match was played under lights (Day Night) and a vector of control variables $(\boldsymbol{X})$ based on previous literature on demand for sport. $v_{i t}$ is an error term.

\subsection{Measuring team quality and longer run uncertainty in ODI cricket}

Similar to Hynds and Smith (1994), Bhattacharya and Smyth (2003) and Sacheti et al. (2014), we include a dummy variable for short run uncertainty of outcome by including a dummy variable for series uncertainty of outcome (Series Certainty). This equals 1 if the series result was decided prior to the match or, in a multi-nation tournament, if the identity of the finalists had been decided before the match. Additionally, we include a measure that captures longer term uncertainty of outcome by assessing the impact of longer term performances on demand. We do this through a variable called Ratings Certainty, which models the ratings uncertainty of outcome of each match as the absolute difference in ODI ratings points (as published by ICC) between the two teams prior to the match. An increase in this variable shows declining uncertainty of outcome and so is expected to lower attendance. We also include the square term of this variable (Ratings Certainty Squared). This allows us to distinguish between small and large changes in uncertainty of outcome in their impact on demand.

We also include a variable called Home Strength, measured by the ICC ODI rating of the home team prior to the match. This will show whether the strength of the home team affects demand for international cricket. Previous literature (Borland and Macdonald, 2003) 
has noted that home team success tends to raise attendance demand. In addition, we include a variable called Opposition Strength, modelling the quality of the opposition team and using the ICC ODI rating of the opposition prior to the match. This will show if spectators are attracted to matches played by strong opponents independent of the strength of the home team. It is important for us that this measure of relative team strengths varies over the sample period. Indeed it does; the best team in the 1980s (i.e. West Indies) was not the best team of the 1990s or 2000s (i.e. Australia). We provide further detail on this in Table 2. For each Test nation, we note the team's highest and lowest ICC ODI rating during our sample years (1981-2015). Each Test nation's ODI rating has varied by at least 29 points (Pakistan) and up to 85 points (Zimbabwe) during the sample period. The case of West Indies is particularly illustrative, as the difference between its highest and lowest rating in the sample period is 66 points, even though the West Indies' highest rating was the highest rating for any team in the sample period (140 points).

\subsection{Other Variables}

The discussion above suggests a number of other variables expected to influence demand for ODI cricket matches apart from uncertainty of outcome and team quality. This list of control variables are provided in Table 1.

We include two economic variables in our model of ODI attendance demand. First, we include Real Income, measured by average weekly earnings in the region the match is held in. This is adjusted for inflation by the monthly national Retail Price Index (RPI) in England and quarterly regional Consumer Price Index (CPI) in Australia. The expected sign for Real Income is ambiguous as professional sport can be either a normal or an inferior good. We also include a variable called Substitutes which equals 1 if a popular match was being simultaneously played in another major professional sport (such as the Australian Open in tennis or European Championships in football). Data limitations mean we are unable, however, to include a direct measure of ticket prices in our model. In any case, as argued by Sacheti et al. (2014), including ticket prices is problematic as they are likely to be endogenous with respect to the opposition. In other words, English and Australian venue authorities set ticket prices according to perceived interest in the opposition. Instead, we include dummy variables for each opposition team. These dummy variables will absorb all time-invariant differences between opposition teams, including fixed price differentials but also fixed team strength differentials. Therefore, the identification of our team strengths and ratings certainty variables relies on variation within teams over time (see Table 2). 
The venue of the match is used as the cross-sectional unit of observation for the model. This is because demand is likely to differ at each venue for reasons that cannot be captured by the other explanatory variables. These reasons include differences in market size, attractiveness of the stadium and local interest in watching live international cricket at each venue. Venue fixed effects also capture any fixed price differentials between venues.

We include a dummy variable called Rain to control for the effect of weather on demand for ODIs. The variable is set equal to 1 if rain reduced the scheduled number of overs in either innings of the ODI and is expected to have a negative coefficient. We also include a dummy variable called Holiday which equals 1 if the match was played on a public holiday. Its expected sign is positive. We do not include population as an explanatory variable as the venue fixed effects are likely to capture the market size, particularly in Australia where venues are rarely supply constrained.

Our model also has a dummy variable called Field Restriction which equals 1 if the match regulations placed a cap on the number of fielders allowed outside the "15-yard circle". This is an ODI specific variable which attempts to capture the impact of a specific policy decision by the ICC intended to raise the popularity of ODI cricket starting from the 1992 World Cup. There have been variants on this fielding restriction rule in the intervening years. Finally, we include a variable called International Days which is the number of days of international cricket (Test, ODI and T20I) played at the venue in the calendar year.

Based on the discussion above, we present our estimating equation of attendance demand for ODI cricket:

\section{Attendance $_{i t}=D_{1}$ Home Strength $_{i t}+D_{2}$ Opposition Strength ${ }_{i t}+D_{3}$ Ratings Certainty $_{i t}+$ $D_{4}$ Ratings Certainty Squared ${ }_{i t}+D_{5}$ Series Certainty ${ }_{i t}+\boldsymbol{X}^{\prime}{ }_{i t} \boldsymbol{\beta}+v_{i}+u_{i t}$}

where $\boldsymbol{X}$ is a vector (including an intercept) of the other control variables which are also likely to affect attendance as listed in Table 1 , and $v_{i}$ is a venue specific error that captures the unobserved heterogeneity between venues. $v_{i}$ is assumed to be independent of the explanatory variables in the Tobit random effects estimates and eliminated in the fixed effects estimates. 


\section{Results and discussion}

\subsection{Descriptive statistics}

Figure 1 shows average ODI attendance over time for matches played by home teams in Australia and England between 1985 and $2015^{3}$. The average ODI attendance per match in Australia during this period was 31,175 spectators, over one and half times the corresponding average of 17,929 spectators in England. The difference is explained in part by the fact that capacities in Australian stadiums are typically higher than in England. For example, the highest capacity in an English cricket stadium is at Lord's in London, which can accommodate up to 30,000 spectators at time of writing ${ }^{4}$, in comparison to almost 100,000 spectators at the Melbourne Cricket Ground (MCG) ${ }^{5}$ in Australia.

Recently, it has been speculated that the rising popularity of T20 cricket, both internationally and domestically, may have affected the demand for ODI cricket. In particular, this effect is likely to have occurred by saturating the market for limited overs cricket given that T20 cricket is in fact a second format of limited overs cricket. Our sample of matches since T20 cricket came into prominence following the inaugural World Twenty20 is limited, but we have nonetheless marked the season on the chart. Whilst aggregate ODI attendance in Australia fell in the years following the first World Twenty20, Figure 1 shows that attendance in Australia has seen a largely downward trend since 1980, meaning it is difficult to attribute the decline in attendance post-2007 to any single factor. In England, ODI attendance has remained largely steady before and after the first World Twenty20. There is thus mixed evidence on how the growth of T20 cricket has affected ODI attendance. In any case, such an effect is likely to be observed over a longer period of time then considered in the present study.

We present some summary statistics of Australian and English attendances over the last thirty years in Table 3. Attendance is simply the officially recorded total attendance for the ODI. Standard deviations are also provided for each venue and opposition team in order to show how spread the data are. Throughout this section, $N$ indicates the number of matches.

Melbourne and Lord's have the highest average attendances in ODIs in Australia and England respectively. Australia is the most popular touring ODI team in England, whilst West Indies is most popular in Australia. Interestingly, whilst day/night matches have

\footnotetext{
${ }^{3}$ The choice of the sample years was informed by availability of nearly complete attendance data for both England and Australia.

${ }^{4}$ Source: www.espncricinfo.com/england/content/ground/57129.html

${ }^{5}$ Source: www.mcg.org.au/The\%20MCG\%20Stadium/Facts\%20and\%20Figures.aspx
} 
substantially higher attendances then day games in Australia, day/night matches have on average lower attendances than day games in England. A consideration of the day vs night weather (especially temperature) in the two countries rationalises this difference. An alternative explanation is as follows. ODI matches in England are frequently sold out, thus reducing the possibility of day/night matches boosting attendance.

The descriptive statistics suggest that England, Australia, South Africa, West Indies and India are the most popular ODI cricket teams in England and Australia. Historically these are the stronger teams, but note that the relative strength of these teams varies over time, as discussed in section 4.4 above. Therefore, from the descriptive statistics alone, it is not clear what impact the relative strengths of these teams and uncertainty of outcome had on attendance demand during the sample period. In order to identify these impacts, we proceed to our econometric analysis. This will exploit the time varying aspect of relative team strengths in our data.

\subsection{Fixed effects estimates (Australia)}

Table 4 provides fixed effects estimates of the effect of uncertainty of outcome on demand for ODI cricket in Australia. The first two columns contain our control variables only. Real Income is statistically significant and has a negative relationship with attendance. This result is not very surprising as previous literature on sport has not found a consistent impact of income on demand (see Borland and Macdonald, 2003). It is possible that ODI cricket is an inferior good in Australia: for example, rising incomes could reflect a greater opportunity cost from spending less time working and watching cricket instead. Alternatively, as incomes rise, consumers might switch from watching relatively inexpensive ODI matches to other sporting events that command a larger premium e.g. Australian Open tennis. In alternative specifications not reported here, we included time trends to identify whether the negative effect of income may have been related to declining ODI attendance over time, but we found this effect was robust to the inclusion of time trends, adding further weight to the possibility that ODI cricket is an inferior good in Australia.

Field Restriction has an insignificant coefficient. However, disentangling the effect of field restriction regulations from other influences over time is difficult, meaning the impact of this ICC policy decision is not clear. Rain has a negative coefficient but its effect is statistically insignificant. Day/Night has a very significant and positive coefficient, with a day/night match attracting over 6,100 spectators more than a day match, on average, in the 
linear estimates. England, South Africa, India and West Indies all raise attendance relative to other away teams, other things being equal. Note that some of this positive effect may be due to a fixed differential between these and other teams but these coefficients do not isolate this effect away from other factors that might impact attendance demand e.g. historical rivalry. Interestingly, the International days variable, which measures the number of days of international cricket played at the venue in the calendar year, has a negative and significant coefficient in the linear model. In Model 1, the result suggests that with other factors controlled for, an additional day of international cricket at the venue will lower attendance at an ODI by 620 spectators, on average. It is likely most local fans budget to watch only a certain number of days of international cricket in each year, meaning this finding is likely to be of interest to venue authorities seeking to maximize attendances.

To examine outcome uncertainty and team strength directly, we include our measures of Home Strength, Opposition Strength and Ratings Certainty in columns 3 and 4. The estimated coefficients on these variables would describe effects on top of any fixed away team affect. Yet none of these coefficients are statistically significant in either the linear (column 3) or log-linear (column 4) specification. This is in contrast to Sacheti et al. (2014), who found a statistically significant relationship between opposition strength and attendance in Test matches in Australia. This suggests that the inter-temporal quality of the teams involved is less important to ODI fans than Test fans in Australia. As noted earlier, we think there are good reasons to suspect that ODI attendance demand might be different to Test attendance demand. Indeed, it could be that ODIs are treated less seriously than Test cricket by Australian fans. In their study of demand for domestic one day cricket in England, Morley and Thomas (2007) distinguish "core" supporters from "floaters". ODI fans in Australia may possibly be "floaters", who are either less informed or care less about the strength of the teams involved compared to Test fans in Australia.

\subsection{Tobit random effects estimates (England)}

Table 5 shows Tobit random effects estimates of the effect of uncertainty of outcome and team strengths on demand for ODI cricket in England.

Real Income is positive and significant across specifications, suggesting that, in contrast to Australia, ODI cricket in England is a normal good. Ratings Certainty has a negative and significant coefficient in both the linear and log-linear specifications, suggesting ODI attendances in England decline with decreasing uncertainty of outcome (meaning a ratings-certain outcome lowers attendance). Ratings Certainty Squared is also significant in 
both the linear and log-linear estimates and has a positive coefficient. Opposition Strength is insignificant in the linear estimates and only slightly significant in the log-linear estimates. This finding is similar to the Australia estimates, where the strength of the opposition team had no significant impact on ODI demand. Home Strength is marginally significant and has a negative coefficient. This suggests that a stronger home team lowers (albeit slightly) demand for ODI cricket in England. However, this result is not particularly robust to the model specification. For example, excluding Ratings Certainty Squared from the estimating equation renders the impact of Home Strength insignificantly different from zero.

For comparison, we have provided venue fixed effects estimates for the England ODIs in Table 6, in line with the model used for Australia ODIs. While there are some differences from the Tobit estimates, it is interesting to note that the long run uncertainty of outcome variables and the income variable are statistically significant in the venue fixed estimates as well. However, for reasons explained above, we focus on the Tobit estimates as the more appropriate model to assess ODI demand in England in light of the capacity constraint issue in several English venues.

The Tobit estimates suggest that ratings certainty is the strongest predictor of ODI demand in England, apart from real income. West Indies, South Africa and England's historical rivals Australia all raise attendance relative to Sri Lanka. There is also some tentative evidence of non-linearity in the relationship between attendance demand and long run uncertainty of outcome in ODIs in England.

These results for ODIs in England provide support for a significant effect of ratings uncertainty of outcome on attendance demand. Apart from a negative effect of increasing income, the strongest predictors of attendance for ODI games in Australia are whether the match was played under lights and whether the opposition was England, South Africa, West Indies or India. In contrast to Sacheti et al. (2014)'s result for Test matches in Australia, the strength of opposition teams is seemingly not as important in affecting ODI demand in Australia. In England, day/night games do not significantly raise attendance. Dawson et al. (2009) find that the team batting first was significantly more likely to win day/night ODI matches, which could be related to the insignificance of day/night matches in raising demand for ODIs. Also, increasing incomes lead to higher attendances for ODIs in England, in contrast to Australia. This suggests that ODI cricket is a normal good in England, in contrast to Australia. The fact that long run uncertainty of outcome raises attendance for ODIs in England also suggests that English ODI audiences may be more discerning than Australia. 


\subsection{Full sample estimates (Australia and England)}

In Table 7, we have provided combined estimates for the full sample including both England and Australia using a Tobit model (with the England observations censored but Australia observations uncensored). Income in the English estimates was converted from Pound sterling into Australian dollars using annual exchange rate data. Two results are of particular interest: firstly, ratings certainty is negative and statistically significant, and secondly, day/night matches significantly raise attendance across the four models. The other team strength and outcome uncertainty variables do not have a significant impact in the full sample.

\section{Discussion and Conclusion}

\subsection{Discussion}

There is some evidence that long run uncertainty of outcome has an impact on demand for ODI cricket: in the main, this evidence is from ODIs in England, where long run uncertainty of outcome is found to raise attendance. This contrasts with recent evidence of the demand for Test cricket (Sacheti et al, 2014) which shows that long run uncertainty has a negligible impact on demand, with the strength of both home and away teams being overwhelmingly more important in both England and Australia.

The strength of the home team is insignificant in ODI cricket in England and Australia. A positive effect of home team success has been frequently noted in other sports, including in Test cricket by Sacheti et al. (2014). The fact that this factor seems less important for ODIs emphasises the fact that the two forms of cricket are differentiated products serving distinct markets.

The impact of the strength of the away team is insignificant in both England and Australia. Indeed, the strongest predictor of attendance in Australia is match timing (whether the match was a day/night game or not). One explanation for the insignificance of home and away strengths in Australia is that ODI cricket demand is more strongly driven by casual cricket watchers, who do not necessarily have a strong preference for watching strong or weak teams. England, South Africa, West Indies and India attract more interest independent of their strength as assessed by ICC rankings, suggesting the attendance decisions of ODI fans in Australia are influenced by factors other than relative team strengths or the absolute strengths of opposition teams. 


\subsection{Concluding remarks}

In contrast to previous literature on international cricket, we examine the determinants of demand for One Day International (ODI) cricket. Using attendance data for over 540 ODI matches played in England and Australia since 1981, we find that, controlling for a series of economic and match specific factors, long run uncertainty of outcome has some impact on demand for ODI cricket in England, but home and away team strengths have no real effect on ODI demand in either England or Australia.

In England, long run ratings certainty has a strongly negative effect on demand, with increasing disparities in strengths of teams leading to lower attendances over time. This result is consistent with Rottenberg's (1956) uncertainty of outcome hypothesis. Home and away team strengths have no significant impact on ODI attendance. This suggests attendance decisions by ODI fans in England are influenced by the prospect of watching a close contest.

In Australia, there is no significant impact of either team strengths or uncertainty of outcome on attendance demand. Rather, the timing of the match (day/night or not) is a stronger predictor of attendance for ODI matches in Australia. Day/night matches are easier to attend during the work week as potential spectators do not have to take much time off work. The fact that increasing incomes lower attendance for ODI cricket in Australia also suggests ODI cricket is an inferior good in that country. Sacheti et al. (2014) find that Test cricket is a normal good in Australia, and the strengths of teams also impact demand in the country. Demand for ODIs in Australia by contrast is not significantly affected by the strengths of the teams. It is thus possible that ODIs satisfy the demand of 'casual' fans in Australia who are either unable or unwilling to spend at least a certain portion of their incomes on attending live cricket matches. As incomes rise, the keener or more discerning cricket fans may switch to the 'higher quality' product of Test cricket, whereas casual cricket watchers' demand remains unchanged, leading to an overall decrease in demand for ODIs with a rise in average incomes. Also, in Australia average ODI attendance is seemingly lowered by a high number of days of international cricket at the venue.

These results carry some policy implications. In Australia, the match timing is crucial in attracting spectators rather than the relative or absolute strengths of teams, although some opposition teams have attracted fans over time independent of their strength. In England, spectator interest is more strongly influenced by how close the match is likely to be, suggesting that matches scheduled against teams which vary widely in ability from the home team are likely to lower attendance. Given that the 2019 World Cup will be held in England, the results here provide some support for the decision to require associate countries to qualify 
for the tournament, insofar as the resulting matches between the countries in the tournament are likely to be closer contests than if all associate countries entered automatically and thus likely lead to higher attendances. However, if excluding associate countries from the tournament widens the gap between them and the Test playing nations, then the viability of future ODIs involving associate countries could be compromised.

The contrast between the results in this paper and those analysing the demand for Test cricket is consistent with a view that the two forms of cricket have markets that operate in different ways. As such, our results provide support for cricketing authorities to devise and implement distinct marketing strategies for the two products. Our results also suggest contrasting drivers of demand for the same product across different countries, suggesting authorities in different countries have to carefully tailor their approaches to maximise attendance and related revenues. Given the evidence that the introduction of T20 cricket can affect the demand for other forms of the game (Paton and Cooke, 2011), it is particularly important that authorities consider the challenge of the growth of well-marketed domestic T20 competitions in recent years.

\section{References}

Austadiums.com (2015). Available from http://austadiums.com as at $10^{\text {th }}$ May 2015.

Australian Bureau of Statistics. (various, 1985-2015). Australian Economic Indicators, cat no. 1350.0. Canberra: Australia Government Publishing Service.

Bhattacharya, M. and Smyth, R. (2003). The game is not the same: The demand for test match cricket in Australia. Australian Economic Papers, 42 (1), pp. 77-90.

Blackham, J. and Chapman, B.J. (2004). The value of Don Bradman: Additional revenue in Australian Ashes tests. Economics Papers: A journal of applied economics and policy, 23 (4), 369-385.

Borland, J. (1987). The Demand for Australian Rules Football. Economic Record, 63 (3), pp. 220-230.

Borland, J. and Macdonald, R. (2003). Demand for sport. Oxford Review of Economic Policy, 19 (4), pp. 478-502.

Chapman, B., Fischer, A. and Maloney, R. (1987). An Analysis of the Determinants of English-Australian Test Cricket Crowds: Estimating the Value of Don Bradman. Mimeo, Centre for Economic Policy Research, Research School of Social Sciences. Australian National University. 
Dawson, P., Morley, B., Paton, D. and Thomas, D. (2009). To bat or not to bat: An examination of match outcomes in day-night limited overs cricket. Journal of the Operational Research Society, 60 (12), pp. 1786-1793.

ESPNcricinfo StatsGuru (various, 2009-15). Available from http://stats.cricinfo.com/guru as at $25^{\text {th }}$ April 2015.

Falter, J.M. and Perignon, C. (2000). Demand for football and intramatch winning probability: an essay on the glorious uncertainty of sports. Applied Economics, vol. 32, pp. 1757-65.

Honoré, B.E. (1992). Trimmed LAD and least squares estimation of truncated and censored regression models with fixed effects. Econometrica, 60 (3), pp. 533-565.

Hynds, M. and Smith, I. (1994). The demand for test match cricket. Applied Economics Letters, 1 (7), pp. 103-106.

International Cricket Council (various, 2001-2012). Reliance ICC Rankings. Available from http://www.icc-cricket.com/match_zone/team_ranking.php as at 25th October 2014.

King, N., Dorian Owen, P. and Audas, R. (2012). Playoff Uncertainty, Match Uncertainty and Attendance at Australian National Rugby League Matches. Economic Record, 88 (281), pp. 262-277.

Koop, G. (2008). Introduction to Econometrics. Chichester: John Wiley \& Sons.

Lemke, R.J., Leonard, M. and Tlhokwane, K. (2010). Estimating attendance at Major League Baseball games for the 2007 season. Journal of Sports Economics, 11 (3), pp. 316348.

Morley, B. and Thomas, D. (2007). Attendance Demand and Core Support: Evidence from Limited-Overs Cricket. Applied Economics, 39 (16-18), pp. 2085-2097.

Office of National Statistics (various, 2004-2014). Annual Survey of Households and Earnings London: Her Majesty's Stationery Office.

Office of National Statistics (various, 1997-2003). New Earnings Survey Part E: Analyses by region, county and small areas. London: Her Majesty's Stationery Office.

Paton, D. and Cooke, A. (2005). Attendance at County Cricket: an economic analysis. Journal of Sports Economics, 6 (1), pp. 24-45.

Paton, D. and Cooke, A. (2011). The Changing Demands of Leisure Time: the emergency of Twenty20 cricket, ch. 18, pp 602-39, in Cameron, S (Ed.) Handbook on the Economics of Leisure. London: Edward Elgar. 
Peel, D. and Thomas, D. (1988). Outcome uncertainty and the demand for football: An analysis of match attendances in the English football league. Scottish Journal of Political Economy, 35 (3), pp. 242-249.

Rottenberg, S. (1956). The baseball players' labour market. Journal of Political Economy, 64 (3), pp. 242-258.

Sacheti, A., Gregory-Smith, I. and Paton, D. (2014). Uncertainty of outcome or strengths of teams: an economic analysis of attendance demand for international cricket. Applied Economics, 46 (17), pp. 2034-2046.

Schofield, J. (1982). The development of first-class cricket in England: An economic analysis. The Journal of Industrial Economics, 30 (4), pp. 337-360.

Wisden Cricketers' Almanack (various, 1981-2014). London: John Wisden Publishing.

Wooldridge, J.M. (2010). Econometric Analysis of Cross Section and Panel Data. Cambridge: MIT Press. 
Table 1: Definitions of variables

\begin{tabular}{|c|c|c|}
\hline Variable & Definition & Source \\
\hline \multicolumn{3}{|l|}{ Dependent variable } \\
\hline Attendance & Match attendance & $\begin{array}{l}\text { Wisden Cricket Almanacks } \\
\text { (1981-2014), various venue } \\
\text { authorities and } \\
\text { austadiums.com }\end{array}$ \\
\hline \multicolumn{3}{|c|}{ Explanatory variables } \\
\hline Ratings Certainty & $\begin{array}{l}\text { Absolute difference in ICC ODI ratings } \\
\text { prior to match }\end{array}$ & $\begin{array}{l}\text { International Cricket Council } \\
\text { web site and news reports* }\end{array}$ \\
\hline $\begin{array}{l}\text { Ratings Certainty } \\
\text { Squared }\end{array}$ & $\begin{array}{l}\text { Square of absolute difference in ODI } \\
\text { ratings prior to match }\end{array}$ & $\begin{array}{l}\text { International Cricket Council } \\
\text { web site and news reports* }\end{array}$ \\
\hline Home Strength & $\begin{array}{l}\text { ICC ODI rating of home team prior to } \\
\text { match }\end{array}$ & $\begin{array}{l}\text { International Cricket Council } \\
\text { web site and news reports* }\end{array}$ \\
\hline Opposition Strength & $\begin{array}{l}\text { ICC ODI rating of opposition team } \\
\text { prior to match }\end{array}$ & $\begin{array}{l}\text { International Cricket Council } \\
\text { web site and news reports* }\end{array}$ \\
\hline Series Certainty & $\begin{array}{l}1 \text { in a bilateral series if series result } \\
\text { decided prior to match; } 1 \text { in a } \\
\text { multilateral series if finalists known } \\
\text { before match; } 0 \text { otherwise }\end{array}$ & ESPNcricinfo \\
\hline Real Income & $\begin{array}{l}\text { Real weekly earnings in region match } \\
\text { played in }\end{array}$ & $\begin{array}{l}\text { Annual Households Survey } \\
\text { and New Earnings Survey (for } \\
\text { England) and Australian } \\
\text { Economic Indicators (for } \\
\text { Australia) }\end{array}$ \\
\hline Rain & $\begin{array}{l}1 \text { if rain reduced number of scheduled } \\
\text { overs per side or if match abandoned } \\
\text { without result; } 0 \text { otherwise }\end{array}$ & ESPNcricinfo \\
\hline Opposition & Dummy variables for opposition teams & \\
\hline Substitutes & $\begin{array}{l}1 \text { if match was played as competing } \\
\text { sporting event took place; } 0 \text { otherwise }\end{array}$ & Various \\
\hline Holiday & $\begin{array}{l}1 \text { if match was played on a public } \\
\text { holiday; } 0 \text { otherwise }\end{array}$ & Various \\
\hline Day/Night & $\begin{array}{l}1 \text { if match was played under lights; } 0 \\
\text { otherwise }\end{array}$ & ESPNcricinfo \\
\hline Field Restriction & $\begin{array}{l}1 \text { if a fielding restriction was in place; } 0 \\
\text { otherwise }\end{array}$ & Various \\
\hline International days & $\begin{array}{l}\text { Number of days of international } \\
\text { cricket played at venue in the season } \\
\text { (Tests, ODIs and T20Is) }\end{array}$ & Various \\
\hline
\end{tabular}

Note: The ICC has recently stopped publishing historical rankings on its web site. Due to this, rankings for mid-2012 onwards have been sourced from various news reports for the month closest to the month the match was held in. 
Table 2: Variation in ICC ODI rating of each Test nation over time (1981-2015)

\begin{tabular}{|l|c|c|c|}
\hline Team & $\begin{array}{l}\text { Highest ICC } \\
\text { ODI rating in } \\
\text { sample period }\end{array}$ & $\begin{array}{l}\text { Lowest ICC ODI } \\
\text { rating in sample } \\
\text { period }\end{array}$ & $\begin{array}{l}\text { Difference between } \\
\text { highest and lowest } \\
\text { ICC ODI rating }\end{array}$ \\
\hline Australia & 137 & 101 & $\mathbf{3 6}$ \\
\hline England & 130 & 84 & $\mathbf{4 6}$ \\
\hline West Indies & 140 & 74 & $\mathbf{6 6}$ \\
\hline $\begin{array}{l}\text { South } \\
\text { Africa }\end{array}$ & 134 & 76 & $\mathbf{5 8}$ \\
\hline India & 122 & 87 & $\mathbf{3 5}$ \\
\hline Pakistan & 121 & 92 & $\mathbf{6 8}$ \\
\hline Sri Lanka & 121 & 53 & $\mathbf{4 3}$ \\
\hline $\begin{array}{l}\text { New } \\
\text { Zealand }\end{array}$ & 119 & 76 & $\mathbf{8 5}$ \\
\hline Zimbabwe & 85 & 0 & $\mathbf{7 4}$ \\
\hline Bangladesh & 75 & 1 & \\
\hline
\end{tabular}


Table 3: Average attendance by venue, opposition and match timing in ODI matches in England and Australia

\begin{tabular}{|c|c|c|c|c|c|c|c|}
\hline Venue & Average & $\begin{array}{l}\text { Std. } \\
\text { Dev. }\end{array}$ & $\mathbf{N}$ & Opposition & Average & Std. Dev. & $\mathbf{N}$ \\
\hline \multicolumn{8}{|l|}{ England 1981-2014 } \\
\hline Lord's & 25,270 & 1,866 & 39 & Australia & 19,201 & 4,715 & 42 \\
\hline Manchester & 19,407 & 2,377 & 23 & Sri Lanka & 18,986 & 5,416 & 19 \\
\hline Southampton & 16,559 & 3,332 & 10 & South Africa & 18,696 & 3,365 & 22 \\
\hline The Oval & 17,896 & 3,410 & 33 & West Indies & 18,281 & 4,781 & 27 \\
\hline Birmingham & 17,061 & 4,252 & 26 & India & 18,394 & 4,882 & 31 \\
\hline Cardiff & 14,342 & 920 & 7 & Pakistan & 17,936 & 4,631 & 29 \\
\hline Chester-Le-Street & 14,433 & 2,031 & 9 & New Zealand & 16,551 & 4,571 & 16 \\
\hline Bristol & 13,954 & 2,078 & 8 & Zimbabwe & 13,085 & 5,625 & 9 \\
\hline Leeds & 13,884 & 2,723 & 21 & Bangladesh & 11,158 & 2,730 & 6 \\
\hline Nottingham & 13,873 & 2,505 & 25 & Kenya & 9,643 & - & 1 \\
\hline Canterbury & 9,643 & - & 1 & & & & \\
\hline Total & 17,929 & 4,932 & 202 & & & & \\
\hline Day/Night matches & 16,940 & 3,460 & 44 & & & & \\
\hline Day Matches & 18,204 & 5,245 & 158 & & & & \\
\hline \multicolumn{8}{|l|}{ Australia 1985-2015 } \\
\hline Melbourne & 46,962 & 18,185 & 93 & West Indies & 35,689 & 16,778 & 58 \\
\hline Sydney & 32,501 & 7,803 & 96 & England & 36,164 & 18,067 & 51 \\
\hline Docklands & 27,716 & 8,241 & 12 & South Africa & 32,034 & 14,590 & 36 \\
\hline Brisbane & 24,505 & 8,362 & 36 & India & 34,156 & 15,119 & 38 \\
\hline Adelaide & 22,749 & 6,584 & 39 & New Zealand & 31,979 & 16,238 & 43 \\
\hline Perth & 18,572 & 6,302 & 40 & Pakistan & 27,687 & 15,205 & 41 \\
\hline Hobart & 11,606 & 2,907 & 19 & Sri Lanka & 25,687 & 12,534 & 54 \\
\hline Cairns & 7,981 & 462 & 2 & Zimbabwe & 18,876 & 11,677 & 11 \\
\hline Darwin & 8,398 & - & 4 & Bangladesh & 8,120 & 406 & 3 \\
\hline Total & 31,175 & 15,987 & 340 & & & & \\
\hline Day/Night matches & 34,004 & 15,740 & 263 & & & & \\
\hline Day Matches & 21,512 & 12,793 & 77 & & & & \\
\hline
\end{tabular}


Table 4: Fixed effects estimates of attendance demand for ODI cricket in Australia with and without uncertainty of outcome and team strength effects, 1985-2015

\begin{tabular}{|c|c|c|c|c|}
\hline \multicolumn{5}{|c|}{$\begin{array}{ll}\text { Dependent variable } & \text { ATTENDANCE }\end{array}$} \\
\hline & Model 1 & Model 2 & Model 3 & Model 4 \\
\hline Variable & Linear & Log-linear & Linear & Log-linear \\
\hline Ratings Certainty & & & $82.37(92.64)$ & $-.00117(.0029)$ \\
\hline $\begin{array}{l}\text { Ratings Certainty } \\
\text { Squared }\end{array}$ & & & $.434(1.05)$ & $0.000004(.00003)$ \\
\hline Home Strength & & & $83.65(79.36)$ & $.003(.002)$ \\
\hline $\begin{array}{l}\text { Opposition } \\
\text { Strength }\end{array}$ & & & $45.87(51.78)$ & $.0026(.0016)$ \\
\hline Series Certainty & & & $2786.83(1588.92)^{*}$ & $-.059(.0499)$ \\
\hline Real Income & $-79.10(14.44)^{* * *}$ & $-.0030(.00045)^{\star * *}$ & $-84.59(15.37)^{* * *}$ & $-.0033(.00048)^{* * *}$ \\
\hline Day/Night & $\begin{array}{l}6120.68 \\
(1776.89)^{\star * *}\end{array}$ & $.201(.0560)^{* * *}$ & $5956.74(1805.74)^{* * *}$ & $.191(.056)^{* * *}$ \\
\hline Field Restriction & $154.47(1617.01)$ & $.0382(.0510)$ & $-815.76(1789.28)$ & $.014(.056)$ \\
\hline International days & $-620.70(295.21)^{* *}$ & $-.0134(.009)$ & $-724.23(299.39)^{* *}$ & $-.017(.009)^{*}$ \\
\hline Rain & $-2657.23(1819.41)$ & $-.0829(.057)$ & $-2803.03(1838.26)$ & $-.0839(.0577)$ \\
\hline Substitutes & $1724.52(1360.66)$ & $.0908(.0429)^{* *}$ & $1962.77(1385.2)$ & $.0888(.0435)^{* *}$ \\
\hline Holiday & $599.69(2776.74)$ & $.0577(.0876)$ & $-613.73(2778.89)$ & $.0625(.087)$ \\
\hline England & $\begin{array}{l}8718.10 \\
(2071.15)^{* * *}\end{array}$ & $.288(.065)^{* * *}$ & $8246.2(2119.87)^{* * *}$ & $.270(.067)^{* * *}$ \\
\hline South Africa & $5706.45(2312.62)^{* *}$ & $.182(.073)^{* *}$ & $5013.37(2527.27)^{* *}$ & $.149(.079)^{*}$ \\
\hline Pakistan & $1034.83(2151.07)$ & $-.0078(-.0679)$ & $143.52(2259.99)$ & $-.044(.071)$ \\
\hline New Zealand & $2846.85(2124.77)$ & $.1204(.0670)^{*}$ & $2894.10(2166.31)$ & $.121(.068)^{*}$ \\
\hline India & $\begin{array}{l}7034.91 \\
(2211.72)^{* * *}\end{array}$ & $.2423(.0698)^{* * *}$ & $6128.22(2296.40)^{* * *}$ & $.202(.072)^{* * *}$ \\
\hline Zimbabwe & $-3343.94(3608.51)$ & $-.186(.113)$ & $514.20(4089.40)$ & $-.066(.129)$ \\
\hline West Indies & $6255.25(2002.44)$ & $.193(.063)^{* * *}$ & $6123.21(2133.38)^{* * *}$ & $.174(.067)^{* * *}$ \\
\hline$N$ & 340 & & & \\
\hline $\begin{array}{l}\text { Hausman test } \\
\text { (Chi squared) }\end{array}$ & $150.80^{* * *}$ & $144.59^{* * *}$ & $140.21^{* * *}$ & $139.25^{* * *}$ \\
\hline Overall $R^{2}$ & 0.124 & 0.164 & 0.1199 & 0.169 \\
\hline
\end{tabular}

Notes:

(i) Standard errors in brackets.

(ii) * Significant at the $10 \%$ level. ** Significant at the 5\% level. ** Significant at the $1 \%$ level.

(iii) Bangladesh was excluded due to a very small number of observations.

(iv) In Models 3 and 4, three matches played by Australia against the World XI in 2005 have been automatically excluded due to no data on team strength (and hence ratings uncertainty) for World XI. 
Table 5: Tobit random effects estimates of attendance demand for ODI cricket in England with and without uncertainty of outcome and team strength effects, 1981-2014

\begin{tabular}{|c|c|c|c|c|}
\hline \multirow[t]{2}{*}{ Dependent variable } & \multicolumn{2}{|c|}{ ATTENDANCE } & \multirow[b]{2}{*}{ Model 3} & \multirow[b]{2}{*}{ Model 4} \\
\hline & Model 1 & Model 2 & & \\
\hline Variable & Linear & Log-linear & Linear & Log-linear \\
\hline Ratings Certainty & & & $-191.80(44.736)^{* * *}$ & $-.013(.0029)^{\star * *}$ \\
\hline $\begin{array}{l}\text { Ratings Certainty } \\
\text { Squared }\end{array}$ & & & $1.724(.692)^{* *}$ & $.00012(.00005)^{* * *}$ \\
\hline Home Strength & & & $-41.60(29.68)$ & $-.0034(.00199)^{*}$ \\
\hline Opposition Strength & & & $39.88(25.45)$ & $.0029(.0017)^{*}$ \\
\hline Series Certainty & & & $386.43(862.76)$ & $.0472(.0584)$ \\
\hline Real Income & $35.56(11.80)^{\star * *}$ & $.0022(.0008)^{* * *}$ & $29.751(11.029)^{* * *}$ & $.0018(.0007)^{\star * *}$ \\
\hline Day/Night & $266.45(856.17)$ & $.0238(.058)$ & $172.26(785.25)$ & $.0171(.0522)$ \\
\hline Field Restriction & 962.07 (1302.26) & $.0666(.0869)$ & $671.50(1244.04)$ & $.036(.081)$ \\
\hline International days & $11.65(180.46$ & $-.0006(.0123)$ & $33.48(165.54)$ & $.0008(.011)$ \\
\hline Rain & $-2252.49(964.13)$ & $-.1480(.066)$ & $-1863.01(876.74)^{\star *}$ & $-.1196(.0586)^{* *}$ \\
\hline Substitutes & $220.47(849.94)$ & $.0208(.058)$ & $-157.18(784.87)$ & $.0093(.0526)$ \\
\hline Holiday & $1185.42(2495.29)$ & $.103(.173)$ & $556.03(2246.66)$ & $.051(.1527)$ \\
\hline Australia & $2197.25(1188.37)^{*}$ & $.161(.081)^{\star *}$ & $\begin{array}{l}3297.15 \\
(1195.37)^{\star * *}\end{array}$ & $.238(.080)^{* * *}$ \\
\hline South Africa & $1752.62(1370.65)$ & $.145(.093)$ & $1793.61(1287.21)$ & $.146(.086)^{*}$ \\
\hline Pakistan & 975.23 (1273.97) & $.091(.087)$ & $1563.26(1171.21)$ & $.132(.078)^{*}$ \\
\hline New Zealand & $245.26(1377.95$ & $.0039(.094)$ & 1057.34 (1308.58) & $.099(.087)$ \\
\hline India & $3095.66(1311.60)^{* *}$ & $.216(.089)^{\star *}$ & $2469.23(1218.91)^{* *}$ & $.1692(.0817)^{\star *}$ \\
\hline Zimbabwe & $\begin{array}{l}-4734.11 \\
(1622.88)^{\star * *}\end{array}$ & $-.350(.110)^{* * *}$ & $-607.10(1817.79)$ & $-.0501(.1202)$ \\
\hline West Indies & $1761.68(1300.26)$ & $.147(.089)^{*}$ & $2511.43(1230.33)^{* *}$ & $.1994(.0826)^{* *}$ \\
\hline Bangladesh & $\begin{array}{l}-7148.73 \\
(1826.73)^{* * *}\end{array}$ & $-.495(.124)^{* * *}$ & $-938.92(2769.94)$ & $-.041(.184)$ \\
\hline$N$ & 202 & & & \\
\hline Wald Chi squared & $70.93 * * *$ & $74.22 * * *$ & $103.28^{* * *}$ & $114.55^{* * *}$ \\
\hline
\end{tabular}

Notes:

(i) Standard errors in brackets.

(ii) * Significant at the $10 \%$ level. ** Significant at the 5\% level. ** Significant at the $1 \%$ level. 
Table 6: Fixed effects estimates of attendance demand for ODI cricket in England with and without uncertainty of outcome and team strength effects, 1981-2014

\begin{tabular}{|c|c|c|c|c|}
\hline \multirow[t]{2}{*}{ Dependent variable } & \multicolumn{2}{|c|}{ ATTENDANCE } & \multirow[b]{2}{*}{ Model 3} & \multirow[b]{2}{*}{ Model 4} \\
\hline & Model 1 & Model 2 & & \\
\hline Variable & Linear & Log-linear & Linear & Log-linear \\
\hline Ratings Certainty & & & $-123.34(27.85)^{* * *}$ & $-.0090(.0018)^{* * *}$ \\
\hline $\begin{array}{l}\text { Ratings Certainty } \\
\text { Squared }\end{array}$ & & & $1.23(.450)^{* * *}$ & $.00009(.00003)^{* * *}$ \\
\hline Home Strength & & & $-32.14(17.84)^{*}$ & $-.0027(.0012)^{* *}$ \\
\hline Opposition Strength & & & $44.06(16.60)^{* * *}$ & $.0033(.001)^{\star * *}$ \\
\hline Series Certainty & & & $94.68(475.70)$ & $.0205(.032)$ \\
\hline Real Income & $24.24(7.37)^{\star * *}$ & $.001(.0005)^{\star \star *}$ & $18.48(7.21)^{\star *}$ & $.00099(.00048)^{\star *}$ \\
\hline Day/Night & $490.43(484.96)$ & $.041(.033)$ & $435.22(461.80)$ & $.0368(.0312)$ \\
\hline Field Restriction & 752.57 (767.19) & $.053(.053)$ & $679.65(760.20)$ & $.0433(.051)$ \\
\hline International days & $-112.22(98.36)$ & $-.01(.007)$ & $-98.26(93.36)$ & $-.009(.006)$ \\
\hline Rain & $-669.73(571.48)$ & $-.041(.039)$ & $-441.56(543.52)$ & $-.0242(.0367)$ \\
\hline Substitutes & $9.74(481.49)$ & $.006(.033)$ & $-144.81(459.13)$ & $-.0069(.0310)$ \\
\hline Holiday & $325.66(1292.13)$ & $.033(0.089)$ & $61.18(1225.14)$ & $.0104(.083)$ \\
\hline Australia & $925.58(691.33)$ & $.067(.047)$ & $1527.14(708.70)^{* *}$ & $.110(.048)^{\star *}$ \\
\hline South Africa & $610.56(787.71)$ & $.062(.047)$ & $639.70(765.26)$ & $.064(.052)$ \\
\hline Pakistan & $19.61(742.34)$ & $.017(.05)$ & 587.85 (718.32) & $.0589(.0485)$ \\
\hline New Zealand & $80.46(846.98)$ & $.019(.059)$ & $1253.82(854.66)$ & $.108(.0578)^{*}$ \\
\hline India & $1152.18(733.23)$ & $.081(.050)$ & $1066.19(708.92)$ & $.0744(.047)$ \\
\hline Zimbabwe & $\begin{array}{l}3968.13 \\
(999.01)^{\star * * *}\end{array}$ & $-.302(.068)^{\star * *}$ & $-759.20(1198.82)$ & $.062(.081)$ \\
\hline West Indies & $662.93(748.18)$ & $.064(.051)$ & 1092.69 (719.70) & $.096(.0486)^{*}$ \\
\hline Bangladesh & $-5044.29(1156.98)$ & $-.362(.079)^{\star \star *}$ & $-223.86(1957.27)$ & $-.0004(.132)$ \\
\hline$N$ & 202 & & & \\
\hline Overall $R^{2}$ & 0.36 & 0.34 & 0.37 & 0.36 \\
\hline
\end{tabular}

\section{Notes:}

(i) Standard errors in brackets.

(ii) * Significant at the $10 \%$ level. ** Significant at the $5 \%$ level. *** Significant at the $1 \%$ level 
Table 7: Tobit random effects estimates of attendance demand for ODI cricket in England and Australia with and without uncertainty of outcome and team strength effects, 19812014

\begin{tabular}{|c|c|c|c|c|}
\hline \multirow[t]{2}{*}{ Dependent variable } & \multicolumn{2}{|c|}{ ATTENDANCE } & \multirow[b]{2}{*}{ Model 3} & \multirow[b]{2}{*}{ Model 4} \\
\hline & Model 1 & Model 2 & & \\
\hline Variable & Linear & Log-linear & Linear & Log-linear \\
\hline Ratings Certainty & & & $-147.63(58.17)^{\star *}$ & $-.005(.002)^{* *}$ \\
\hline $\begin{array}{l}\text { Ratings Certainty } \\
\text { Squared }\end{array}$ & & & $.7786(.5136)$ & $.00002(.00002)$ \\
\hline Home Strength & & & $-12.27(46.94)$ & $-.0004(.0016)$ \\
\hline Opposition Strength & & & $35.93(29.46)$ & $.0017(.001)^{*}$ \\
\hline Series Certainty & & & $-1206.31(1247.73)$ & $-.003(.042)$ \\
\hline Real Income & $-22.45(9.38)^{* *}$ & $-.0009(.0003)^{\star * *}$ & $-10.46(10.55)$ & $-.0003(.0004)$ \\
\hline Day/Night & $\begin{array}{l}4383.75( \\
1312.23)^{* * *}\end{array}$ & $.158(.045)^{* * *}$ & $\begin{array}{l}4373.33 \\
(1309.83)^{* * *}\end{array}$ & $.15(.044)^{* * *}$ \\
\hline Field Restriction & $-56.91(1276.97)$ & $.028(.044)$ & $-824.38(1274.83)$ & $-.0022(.043)$ \\
\hline International days & $-54.48(229.94)$ & $.004(.008)$ & $-162.60(230.99)$ & $-.0015(.00)$ \\
\hline Rain & $-2611.58(1388.43)^{*}$ & $-.082(.047)^{*}$ & $-2676.03(1371.79)^{*}$ & $-.083(.046)^{*}$ \\
\hline Substitutes & $1689.49(1094.65)$ & $.080(.037)^{* *}$ & $1904.29(1094.31)^{*}$ & $.083(.037)^{* *}$ \\
\hline Holiday & $1207.36(2418.61)$ & $.112(.083)$ & $1275.40(2386.11)$ & $.12(.081)$ \\
\hline Bangladesh & $\begin{array}{l}-14459.60 \\
(3919.18)^{\star * *}\end{array}$ & $-.72(.14)^{* * *}$ & $-7322.23(4677.63)$ & $-.38(.16)^{* *}$ \\
\hline India & $-17.67(1716.69)$ & $.0087(.059)$ & $-638.99(1723.46)$ & $-.012(.06)$ \\
\hline New Zealand & $\begin{array}{l}-4195.61 \\
(1720.57)^{* *}\end{array}$ & $-.127(.059)^{\star *}$ & $\begin{array}{l}-4284.72 \\
(1739.84)^{* *}\end{array}$ & $-.13(.06)^{* *}$ \\
\hline Pakistan & $\begin{array}{l}-4280.18 \\
(1668.10)^{* * *}\end{array}$ & $-.168(.057)^{\star \star *}$ & $\begin{array}{l}-5199.56 \\
(1678.87)^{* * *}\end{array}$ & $-.20(.057)^{\star \star \star *}$ \\
\hline South Africa & $-591.40(1791.25)$ & $-.015(.061)$ & $-1604.06(1823.77)$ & $-.051(.062)$ \\
\hline Sri Lanka & $\begin{array}{l}-6505.07 \\
(1637.20)^{\star * *}\end{array}$ & $-.22(.056)^{* * *}$ & $\begin{array}{l}-6475.66 \\
(1642.72)^{* * *}\end{array}$ & $-.21(.056)^{* * *}$ \\
\hline West Indies & $-454.82(1610.54)$ & $-.022(.055)$ & $-405.23(1608.74)$ & $-.019(.054)$ \\
\hline Zimbabwe & $\begin{array}{l}-9939.99 \\
(2606.20)^{* * *}\end{array}$ & $-.47(.089)^{* *}$ & $-5639.45(2924.09)^{*}$ & $-.29(.099)^{\star * *}$ \\
\hline$N$ & 542 & & & \\
\hline Wald Chi squared & 69.71 & 103.53 & 88.33 & 134.54 \\
\hline
\end{tabular}

Notes:

(i) Standard errors in brackets

(ii) * Significant at the 10\% level. ** Significant at the 5\% level. ** Significant at the $1 \%$ level. 
Figure 1: Average attendance for ODI matches played in England and Australia, 1985-2014

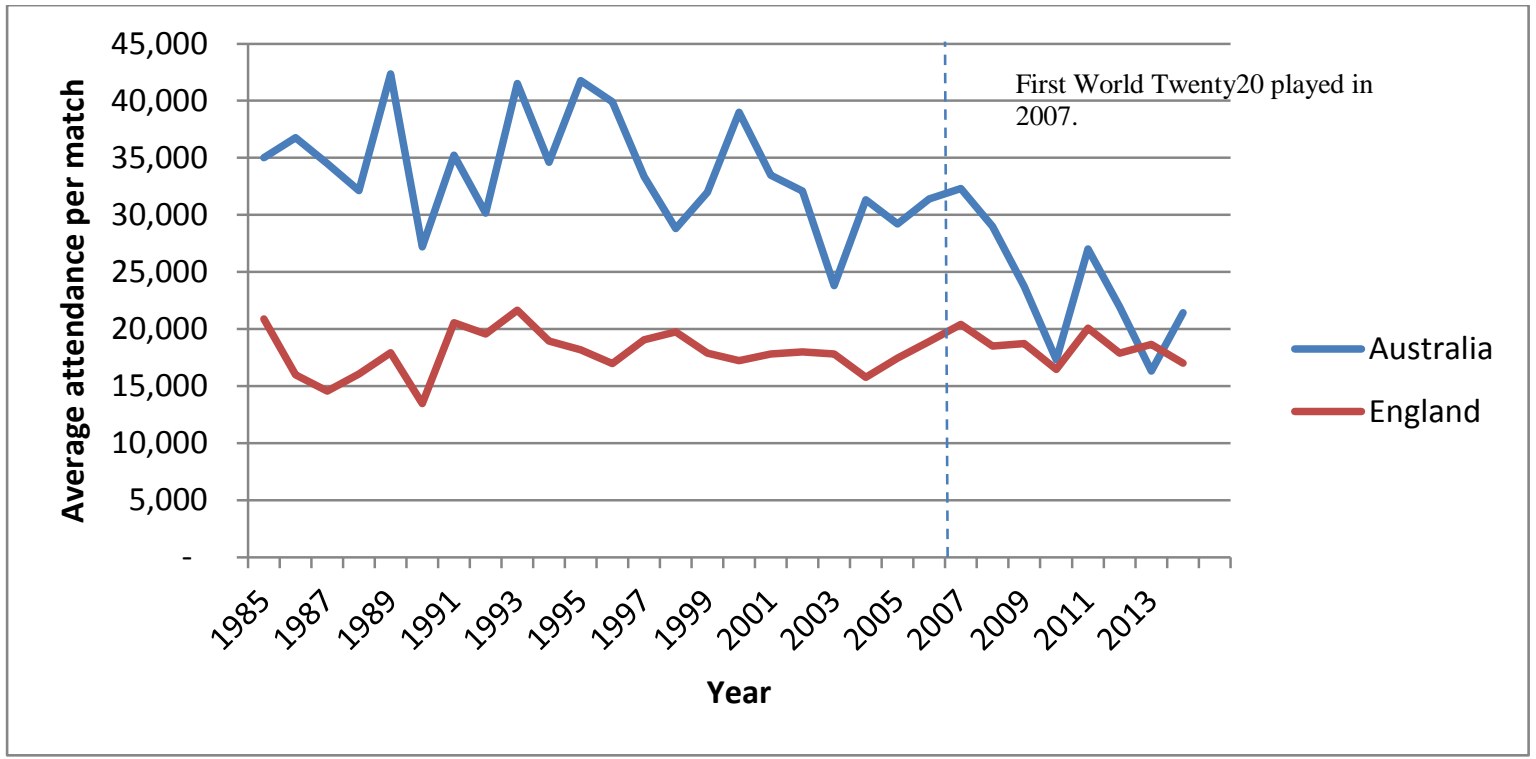

Note: Attendances for England are for ODI matches played by the English cricket team in England during the sample period, and attendances for Australia are for ODI matches played by the Australian cricket team in Australia during the sample period. 